\title{
Predicting Increased Blood Pressure Using Machine Learning
}

\author{
Hudson Fernandes Golino, ${ }^{1}$ Liliany Souza de Brito Amaral, ${ }^{2}$ \\ Stenio Fernando Pimentel Duarte, ${ }^{3}$ Cristiano Mauro Assis Gomes, ${ }^{1}$ Telma de Jesus Soares, ${ }^{2}$ \\ Luciana Araujo dos Reis, ${ }^{3}$ and Joselito Santos ${ }^{3}$ \\ ${ }^{1}$ Laboratório de Investigação da Arquitetura Cognitiva, Universidade Federal de Minas Gerais, 30000-000 Belo Horizonte, \\ Minas Gerais, MG, Brazil \\ ${ }^{2}$ Instituto Multidisciplinar de Saúde, Universidade Federal da Bahia, 40000-000 Bahia, BA, Brazil \\ ${ }^{3}$ Núcleo de Pós-Graduação, Pesquisa e Extenção, Faculdade Independente do Nordeste, São Luís Avenue, 1305, \\ 45000-000 Candeias, Vitória da Conquista, BA, Brazil
}

Correspondence should be addressed to Hudson Fernandes Golino; hfgolino@gmail.com

Received 16 August 2013; Revised 12 October 2013; Accepted 16 November 2013; Published 23 January 2014

Academic Editor: Yuichiro Yano

Copyright (C) 2014 Hudson Fernandes Golino et al. This is an open access article distributed under the Creative Commons Attribution License, which permits unrestricted use, distribution, and reproduction in any medium, provided the original work is properly cited.

\begin{abstract}
The present study investigates the prediction of increased blood pressure by body mass index (BMI), waist (WC) and hip circumference (HC), and waist hip ratio (WHR) using a machine learning technique named classification tree. Data were collected from 400 college students ( $56.3 \%$ women) from 16 to 63 years old. Fifteen trees were calculated in the training group for each sex, using different numbers and combinations of predictors. The result shows that for women BMI, WC, and WHR are the combination that produces the best prediction, since it has the lowest deviance (87.42), misclassification (.19), and the higher pseudo $R^{2}(.43)$. This model presented a sensitivity of $80.86 \%$ and specificity of $81.22 \%$ in the training set and, respectively, $45.65 \%$ and $65.15 \%$ in the test sample. For men BMI, WC, HC, and WHC showed the best prediction with the lowest deviance (57.25), misclassification (.16), and the higher pseudo $R^{2}(.46)$. This model had a sensitivity of $72 \%$ and specificity of $86.25 \%$ in the training set and, respectively, $58.38 \%$ and $69.70 \%$ in the test set. Finally, the result from the classification tree analysis was compared with traditional logistic regression, indicating that the former outperformed the latter in terms of predictive power.
\end{abstract}

\section{Introduction}

Obesity (body mass index $>29.9 \mathrm{~kg} / \mathrm{m}^{2}$ ) has been considered a global public health problem due to its high prevalence and high morbidity [1]. In fact, the prevalence of obesity has increased substantially, both in developed and in under development countries. In the United States, for example, it is estimated that $35.5 \%$ of women and $32.2 \%$ of adult men present obesity [2]. The Brazilian Institute of Geography and Statistics (IBGE) indicates that $50.1 \%$ of men and $48 \%$ of women have overweight $\left(25 \mathrm{~kg} / \mathrm{m}^{2} \leq \mathrm{BMI}<29.9 \mathrm{~kg} / \mathrm{m}^{2}\right)$, while $12.4 \%$ of men and $16.9 \%$ of women are suffering from obesity in Brazil [3].

The high risk attributed to obesity is related particularly to its association with increased risk factors for cardiovascular disease, notably hypertension $[4,5]$. In order to adopt early preventive/therapeutic actions to minimize the risk of cardiovascular events in obese individuals, methods that can predict hypertension using low cost procedures are necessary, especially in underdeveloped and in developing countries.

Body mass index (BMI), waist circumference (WC), hip circumference (HC), and waist-hip ratio (WHR) are among the most practical and cost effective measures for evaluation of obesity, with the advantage that both WC and WHR present positive correlations with the amount of visceral fat, and together effectively predict cardiovascular risk $[6,7]$. Furthermore, these anthropometric measures are predictors of metabolic factors and multiple health risks $[8,9]$. Yong et al. [9] used the ROC curve analysis to verify the predictive power of WC, WHR, and BMI on blood pressure in 722 Chinese 
adults. WC presented a cutoff of $89.05 \mathrm{~cm}$ for men (sensibility $=70 \%$, specificity $=42 \%, P<0.001)$ and $90.90 \mathrm{~cm}$ for women (sensibility $=60 \%$, specificity $=67 \%, P<0.001)$. Waist-hip ratio was not a significant predictor for men $(P=0.369)$ or women $(P=0.070)$, with a cutoff of $0.92 \mathrm{~cm}$ for the first (sensibility $=67 \%$, specificity $=54 \%$ ) and $0.85 \mathrm{~cm}$ for the second (sensibility $=83 \%$, specificity $=40 \%$ ). Finally, BMI presented a cutoff of $23 \mathrm{~kg} / \mathrm{m}^{2}$ for men (sensibility $=76 \%$, specificity $=49 \%, P<0.001)$ and $23.3 \mathrm{~kg} / \mathrm{m}^{2}$ for women (sensibility $=75 \%$, specificity $=59 \%, P<0.001$ ). Although less employed in the study of health conditions related to obesity, hip circumference is pointed as a variable that can increase the predictive power of the other anthropometric variables and should be included in the obesity studies [10]. It seems that the combination of multiple anthropometric variables increases the sensibility of the prediction $[11,12]$.

From the usual methods employed to study the relationship between anthropometric variables and obesity, the receiver-operating characteristic (ROC) curve analysis is the technique used to provide and to verify the quality of the cutoff points. This statistical method is highly recommended in epidemiological studies [13] because it can describe the accuracy of a variable to classify people into relevant clinical groups. However, the ROC curve methodology is not an informative technique to evaluate the contribution of an additional variable to the model [14]. The use of the ROC curve analysis became limited to investigate incremental validity, that is, the improvement in the prediction or in the amount of variance explained when an additional variable enters the model. Thus, in order to discover the strength of any combination of WC, HC, and WHR to predict hypertension, it is necessary to employ a statistical method that can provide sensitive information about incremental validity.

Health researches could benefit from employing machine learning techniques to verify the combination of variables that best predict a given outcome, as well as to verify their cutoff values. Machine learning is a relatively new science field focused on the construction and study of systems that can automatically learn from data [14], generating high accurate predictive models. Although incipient, machine learning methods are already in use in the health literature, as in the sustained weight loss study [15], in the evaluation of program cost effectiveness [16], in the obesity prediction [17], in the classification of prostate cancer levels [18], and in the classification of electronic patient records [19]. In 2013, The Microsoft Research Machine Learning Summit presented new applications of the machine learning techniques in health science, including applications to analyze clinical [20], genetic [21], and medical image data [22].

Among the techniques of machine learning, the classification and regression tree (CART) is of special interest for health studies, since it is useful: (1) to discover which variable, or combination of variables, better predicts a given outcome (e.g., presence of increased blood pressure,) and (2) to identify the cutoff values for each variable that maximally predicts the chosen outcome.

CART is a type of supervised learning technique [14] for recursively partitioning a feature space into several parts (or nodes), based on the relationship between an outcome variable and one or more predictors. The recursive binary partition is used to achieve a solution that divide the feature space into more pure nodes, that is, into a classification with the highest amount of cases with the same condition (e.g., hypertension). In sum, CART works as follows: (1) iteratively split variables into groups; (2) split the data where it is maximally predictive and (3) maximize the amount of homogeneity in each group [23].

Two main indexes, misclassification and deviance, can be used to indicate the quality of the prediction. Hastie et al. [14] explain how both work: In a node $m$, representing region $R_{m}$, with $N_{m}$ observations, let

$$
\widehat{p}_{m k}=\frac{1}{N_{m}} \sum_{x_{i} \in R_{m}} I\left(y_{i}=k\right)
$$

the proportion of class $k$ observations in node $m$. We classify the observations in node $m$ to class $(m)=\arg \max _{k} \widehat{p}_{m k}$, the majority class in node $m$. Different measures of node impurity $(\cdots)$ include the following:

Misclassification error: $\left(1 / N_{m}\right) \sum_{i \in R_{m}} I\left(y_{i} \neq k(m)\right)=1-$ $\widehat{p}_{m k}$.

Cross entropy or deviance: $-\sum_{k=1}^{K} \widehat{p}_{m k} \log \widehat{p}_{m k}$ (p. 309).

Misclassification is the index indicating the total amount of wrong predictions made or its rate (number of wrong predictions/total number of cases). Deviance is an index that is sensible to both the misclassification and the purity of the feature space partitions. As pointed by Hastie et al. [14] and by Golino et al. deviance is a better index to compare different models than misclassification, since it is more sensitive to node purity.

The present study has as the main goal to introduce and to apply the machine learning technique named classification and regression tree (CART) in the context of increased blood pressure. The machine learning field is a set of innovative techniques that provides state-of-the-art predictions in terms of accuracy. CART is becoming popular in different science fields since its interpretability is straightforward; the result of the prediction is easily understandable by experts of the field; it is applicable to a wide range of problems, can use any kind of variable as predictor, is a nonparametric technique, and is sensible to the impact of additional variables in the predictive model. Through the application of the CART analysis we expect to contribute with future studies focusing on the prediction of increased blood pressure by any kind of variable (e.g., genes, daily life habits, biomarkers, etc.). Additionally, we are going to compare the results from the CART analysis with traditional logistic regression analysis, in terms of strength of the prediction (pseudo- $R^{2}$ and AUC). In the present study we will analyze which variable, or combination of variables (BMI, WC, HC, and WHR), better predicts increased blood pressure (prehypertension or hypertension) and which cutoff values are maximally predictive of it. Fifteen models, or trees, with different number and combination of predictors will be compared for each sex, in a training sample. Then, the best tree will be tested in a testing sample for cross validation. 


\section{Materials and Methods}

2.1. Sample and Measures. The data was collected in a convenience sample composed of 400 undergraduate students (56.3\% women) aged between 16 and 63 years old (mean $=$ 23.14 and standard deviation $=6.03$ ), from a private university of Vitória da Conquista, Bahia, Brazil. All participants signed an informed consent agreeing to participate in the research. Weight was measured using a digital scale (Model B530, Plebal Plenna Ltda., SP, Brazil), to the closest $0.1 \mathrm{Kg}$. Height was measured using a stiff tape placed vertically on a flat wall, on subjects standing erect and head in the Frankfurt plane [24]. BMI was calculated using these measurements. WC was measured at the midpoint between the lower border of the rib cage and the iliac crest, and HC was measured at the greater gluteal curvature, both using a 1.5 meters' tape (ISP Eletromédica, Brazil), and recorded to the closest $0.1 \mathrm{~cm}$. Blood pressure was measured using a manually inflatable blood pressure monitor (HEM-403INT, Omron Healthcare, Japan). All anthropometric measurements were repeated three times (the mean value was used in the data analysis) and were taken by previously trained research assistants.

2.2. Data Analysis. The systolic blood pressure was assessed and the subjects with increased blood pressure were identified. The data were first split into two subsets, one for each sex. Then, each subset was randomly split into two sets (training and testing) with almost the same number of people for cross-validation. The dataset is freely available in a web repository for reproducible purposes [25, 26]: (1) women's dataset can be downloaded at http://dx.doi.org/10.6084/m9.figshare.845664; (2) men's dataset can be downloaded at http://dx.doi.org/10.6084/m9. figshare.845665. All analyses were made using the tree package [27] from the $\mathrm{R}$ software. In the current study the tree classification procedure was fitted by binary recursive partitioning using as outcome the presence of increased blood pressure: at least prehypertension (systolic blood pressure > $120.0 \mathrm{mmHg}$ ) for women and hypertension (systolic blood pressure $>140.0 \mathrm{mmHg}$ ) for men. We are not investigating systolic hypertension in the weman sample because only $8 \%$ of them presented a systolic blood pressure equal to or greater than $140 \mathrm{mmHg}$. When the prevalence of one category of the outcome variable is very low, the classification tree fits a model that only predicts more abundant category. This problem is typical of the machine learning methods, which suffer in the presence of unbalanced datasets [28]. Geurts et al. [28] suggest to undersample the majority class in order to solve the problem, but we decided not to follow their advice, since our dataset contains only 18 women with systolic hypertension. To balance the data, by undersampling the majority class (no systolic hypertension), we would have created another issue: a very low sample size that would preclude the cross-validation. So, we decided to investigate prehypertension in the women sample, since $42 \%$ of them presented systolic blood pressure greater than $120 \mathrm{mmHg}$. The predictive variables included in the models were BMI, WC, HC, and WHR.
Fifteen random trees were calculated (grown) from the training set for each sex, in order to identify which variables, or which combination of variables, were suitable to predict the presence of increased blood pressure. Each random tree had one or more predictors, as can be seen in Table 2. The quality of each model or tree was verified using the misclassification error rate and deviance. A pseudo $R^{2}$ was calculated for each model, using the following formulae:

$$
\text { Pseudo } R^{2}=1-\left(\frac{\text { Deviance }}{\text { SSY }}\right)
$$

where SSY represents the response sum of squares.

All the ethical principles contained in the Declaration of Helsinki were followed in the current study, as well as all the Brazilian specific laws.

\section{Results and Discussion}

None of the variables employed in the current study presented a normal distribution, as pointed by the ShapiroWilk's test of normality (see Table 1). Men presented a higher value of systolic blood pressure (median $=130 \mathrm{mmHg}$ ), BMI $\left(\right.$ median $\left.=24 \mathrm{~kg} / \mathrm{m}^{2}\right), \mathrm{WC}($ median $=84 \mathrm{~cm}), \mathrm{HC}($ median $=$ $103 \mathrm{~cm}$ ), and WHR (median $=0.83)$ than women. The latter showed the following medians: a SBP of $117 \mathrm{mmHg}$, a BMI of $22 \mathrm{~kg} / \mathrm{m}^{2}$, a WC of $76 \mathrm{~cm}$, a HC of $100 \mathrm{~cm}$, and a WHR of 0.76 .

Systolic blood pressure presented a moderate correlation with all the anthropometric variables. Only $10.89 \%$ of SBP's variance was explained by $\mathrm{BMI}, 12.25 \%$ was explained by WC, $6.25 \%$ by $\mathrm{HC}$, and $9.61 \%$ by WHR. Increased blood pressure was found in $42 \%$ of women (SBP > $120 \mathrm{mmHg}$ ) and in $47 \%$ of men (SBP > $140 \mathrm{mmHg}$ ). Table 2 shows the deviance, misclassification, and pseudo- $R^{2}$ for each of the fifteen models investigated in the training sample. Waist circumference alone was the worst predictor for the women sample (tree 2), since it presented a deviance of 149.30, a misclassification error rate of 0.40 , and a pseudo- $R^{2}$ of only 0.03 . Tree 13 presented the best model, with the lowest deviance (87.42), a misclassification error rate of 0.19 , and a pseudo- $R^{2}$ of 0.43 . Comparing the variables alone, body mass index was the best predictor, explaining $32 \%$ of the variance of increased systolic blood pressure for women, against only $3 \%$ for waist circumference and hip circumference and 9\% of waist-hip ratio. When added to BMI as predictors, WC and $\mathrm{HC}$ worsen the prediction, decreasing the percentage of explained variance from $32 \%$ to $29 \%$ and the misclassification from 0.27 to 0.26 and increasing the deviance from 104.50 to 109.50 and 108.90, respectively. All combinations of three variables provided a better prediction than the variables alone or combined two by two. Tree 11, for example, had BMI, WC and $\mathrm{HC}$ as predictors of increased blood pressure and resulted in a better model then tree 1 (BMI alone), decreasing deviance from 104.50 to 94.24 , misclassification from 0.26 to 0.22 and increasing the percentage of explained variance from $32 \%$ to $39 \%$. So, WC and HC together with BMI have an incremental validity that adds $4 \%$ of explanation to the predictive model. However, the best model, represented by tree 13, showed that WC and WHR combined with BMI add $11 \%$ of variance 
TABLE 1: Descriptive statistics for SBP, BMI, WC, HC, and WHR; prevalence of obesity for woman and man; test of normality and correlations.

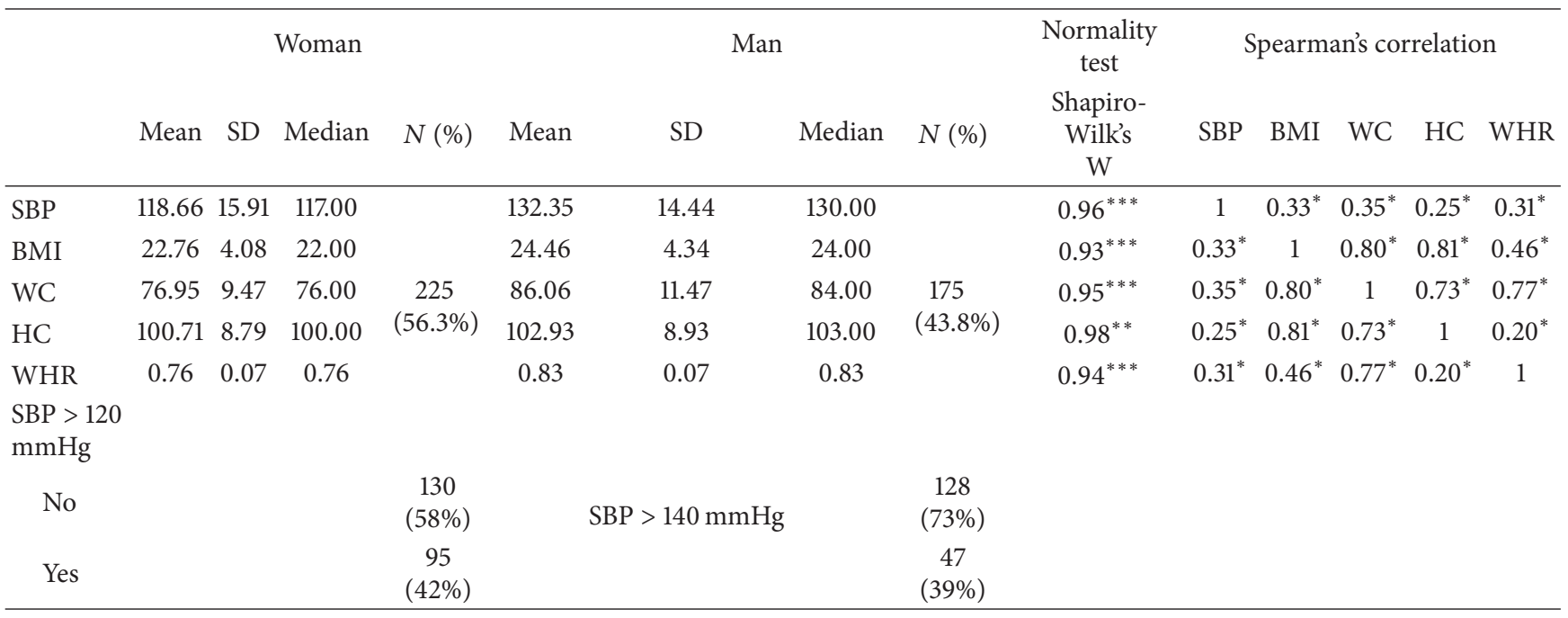

* Significant at the 0.01 level.

** Significant at the 0.05 level.

*** Significant at the 0.001 level.

SBP: systolic blood pressure, BMI: body mass index, WC: waist circumference, HC: hip circumference, WHR: waist-hip ratio. Notice that the endpoint for women is SBP greater than $120 \mathrm{mmHg}$ (prehypertension), while for men is SBP greater than $140 \mathrm{mmHg}$ (hypertension).

TABLE 2: Predictors, deviance, misclassification, and pseudo- $R^{2}$ by tree.

\begin{tabular}{|c|c|c|c|c|c|c|c|}
\hline \multirow[b]{2}{*}{ Tree } & \multirow[b]{2}{*}{ Predictors } & \multicolumn{3}{|c|}{ Women } & \multicolumn{3}{|c|}{ Men } \\
\hline & & Deviance & $\begin{array}{c}\text { Misclassification } \\
\text { error rate }\end{array}$ & $\begin{array}{c}\text { Pseudo- } \\
R^{2}\end{array}$ & Deviance & $\begin{array}{c}\text { Misclassification } \\
\text { error rate }\end{array}$ & $\begin{array}{c}\text { Pseudo- } \\
R^{2}\end{array}$ \\
\hline 1 & BMI & 104.50 & 0.27 & 0.32 & 89.35 & 0.26 & 0.16 \\
\hline 2 & WC & 149.30 & 0.40 & 0.03 & 92.96 & 0.27 & 0.13 \\
\hline 3 & $\mathrm{HC}$ & 148.90 & 0.41 & 0.03 & 89.59 & 0.26 & 0.16 \\
\hline 4 & WHR & 139.50 & 0.33 & 0.09 & 95.09 & 0.29 & 0.11 \\
\hline 5 & $\mathrm{BMI}+\mathrm{WC}$ & 109.50 & 0.26 & 0.29 & 71.07 & 0.21 & 0.33 \\
\hline 6 & $\mathrm{BMI}+\mathrm{HC}$ & 108.10 & 0.26 & 0.29 & 80.17 & 0.25 & 0.25 \\
\hline 7 & $\mathrm{BMI}+\mathrm{WHR}$ & 104.60 & 0.23 & 0.32 & 79.9 & 0.23 & 0.25 \\
\hline 8 & $\mathrm{WC}+\mathrm{HC}$ & $149.30^{*}$ & 0.40 & 0.03 & 82.19 & 0.23 & 0.23 \\
\hline 9 & $\mathrm{WC}+\mathrm{WHR}$ & 115.90 & 0.26 & 0.24 & 69.54 & 0.24 & 0.35 \\
\hline 10 & $\mathrm{HC}+\mathrm{WHR}$ & 118.60 & 0.29 & 0.23 & 76 & 0.21 & 0.29 \\
\hline 11 & $\mathrm{BMI}+\mathrm{WC}+\mathrm{HC}$ & 94.24 & 0.22 & 0.39 & 72.66 & 0.23 & 0.32 \\
\hline 12 & $\mathrm{WC}+\mathrm{HC}+\mathrm{WHR}$ & 99.17 & 0.23 & 0.35 & 61.5 & 0.17 & 0.42 \\
\hline 13 & $\mathrm{BMI}+\mathrm{WC}+\mathrm{WHR}$ & 87.42 & 0.19 & 0.43 & 64.98 & 0.19 & 0.39 \\
\hline 14 & $\mathrm{BMI}+\mathrm{HC}+\mathrm{WHR}$ & 101.10 & 0.22 & 0.34 & 61.93 & 0.16 & 0.42 \\
\hline 15 & $\mathrm{BMI}+\mathrm{WC}+\mathrm{HC}+\mathrm{WHR}$ & 89.46 & 0.19 & 0.42 & 57.25 & 0.16 & 0.46 \\
\hline
\end{tabular}

${ }^{*}$ HC dropped out.

Notice that the endpoint for women is systolic blood pressure greater than $120 \mathrm{mmHg}$ (prehypertension), while for men is greater than $140 \mathrm{mmHg}$ (hypertension).

explanation to the predictive model, compared to BMI alone (tree 1), decrease the percentage of misclassification from $26 \%$ to $19 \%$, and decrease deviance from 104.50 to 87.42 . So, WC and WHR have a considerable impact on the prediction of increased blood pressure in women when combined with BMI, presenting incremental validity over the latter.

Considering the men's result, waist-hip ratio alone (tree 4) presented the worst prediction model, with deviance of
95.09, misclassification error rate of 0.29 , and pseudo- $R^{2}$ of 0.11 . Tree 15 presented the best model, with the lowest deviance (57.25), a misclassification error rate of 0.16 , and a pseudo- $R^{2}$ of 0.46 . Comparing the variables alone, body mass index was the best predictor, explaining $16 \%$ of the variance of increased systolic blood pressure for men, with a deviance of 89.35 and a misclassification of 0.26 , a result slightly better than tree 3 in which $\mathrm{HC}$ alone explained the 


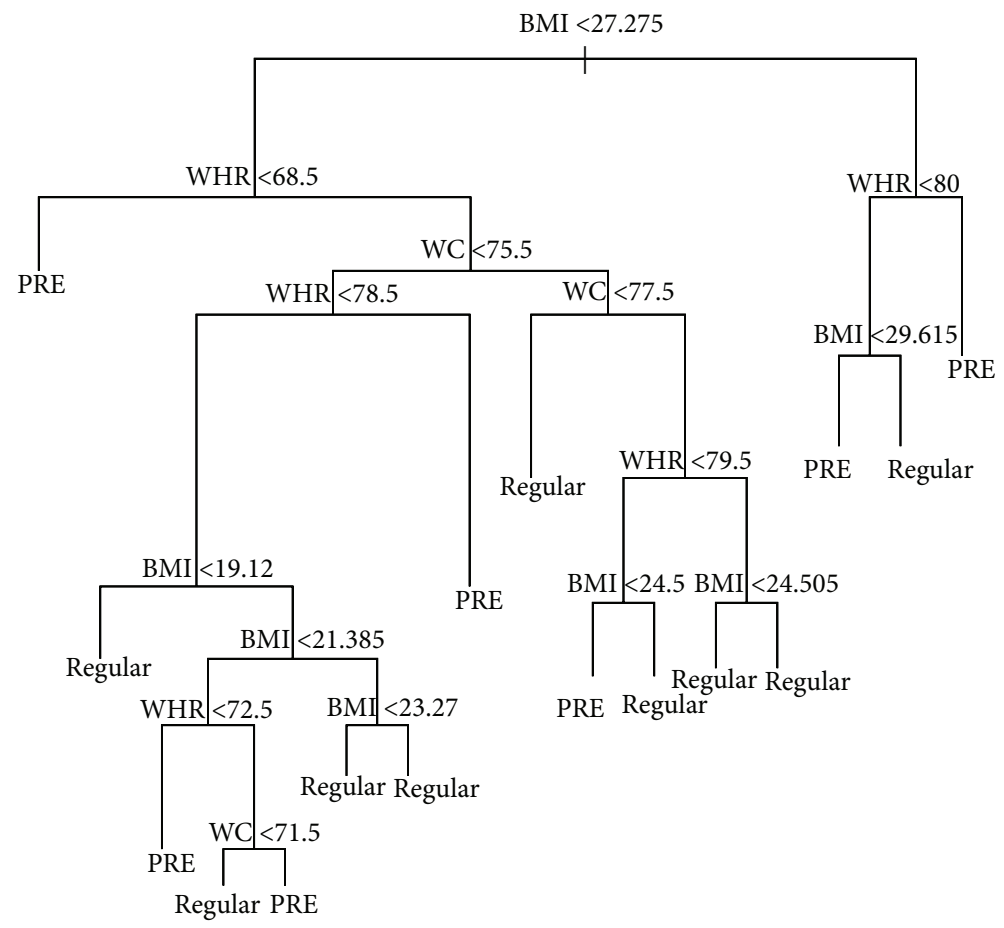

FIGURE 1: Best model for women. Notice that the endpoint for women is systolic blood pressure greater than $120 \mathrm{mmHg}$ (prehypertension).

same amount of increased SBP's variance with deviance of 89.59 and a misclassification of 0.26 . When added to BMI as predictors, WC, $\mathrm{HC}$, and WHR increase the percentage of variance explanation to $33 \%, 25 \%$, and $25 \%$, respectively, with deviance of $71.07,80.17$, and 79.90 and with misclassification error rate of $0.21,0.25$, and 0.23 . All combinations of two variables lead to a better prediction than every variable alone. When added to BMI and WC, hip circumference worsens the prediction by decreasing the percentage of increased systolic blood pressure's variance explanation from 33\% (tree 5) to $32 \%$ (tree 11), increasing deviance from 71.07 to 72.66 , and misclassification error rate from 0.21 to 0.23 . However, when waist-hip ratio is added to $\mathrm{BMI}, \mathrm{WC}$, and $\mathrm{HC}$ as predictors, deviance, misclassification, and pseudo- $R^{2}$ are improved. If we compare tree 15 with tree 1 it is possible to argue that WC, HC, and WHR together present incremental validity in the prediction of increased systolic blood pressure in men, increasing $30 \%$ of its variance explanation, improving $10 \%$ of misclassification, and decreasing deviance from 89.35 to 57.25 .

Figure 1 shows the tree that best predicts increased blood pressure for women (SBP > $120 \mathrm{mmHg}$ ) in the training sample. The predictors are distributed in several nodes and are always split in a specific cutoff value. The predictions made are at the bottom of the tree. For example, when BMI is smaller than $27.27 \mathrm{~kg} / \mathrm{m}^{2}$ and WHR is smaller than $.685 \mathrm{~cm}$, the person is classified as having systolic pre-hypertension (classified as PRE). When BMI is higher than $27.27 \mathrm{~kg} / \mathrm{m}^{2}$ and WHR is higher than 0.80 , the person is also classified as having systolic pre-hypertension (classified as PRE). Averaging the percentage of women with increased blood pressure (or systolic pre-hypertension) classified as having pre-hypertension in each node results in a correct prediction of $80.86 \%$; in other words this is the overall tree sensibility. In the same line of reasoning, averaging the percentage of women with regular blood pressure classified as having a regular pressure in each node results in a correct prediction of $81.22 \%$; in other words this is the overall tree specificity. However, the cross-validation of tree 13 in women's testing sample showed that the sensibility decreased to $45.65 \%$ and the specificity to $65.15 \%$. The percentage of women with SBP greater than $120 \mathrm{mmHg}$ in the training sample was $43.75 \%$ and in the testing sample was $41.07 \%$.

Figure 2 shows the tree that best predicts increased blood pressure for men (SBP $\geq 140 \mathrm{mmHg}$ ) in the training sample. The interpretation of Figure 2 is the same as Figure 2. For example, when HC is higher than 110.5, WHR is higher than 0.865 , and BMI is greater than 31.45 , the person is classified as having systolic hypertension (HYPER). Actually, 67\% of men with these characteristics have a systolic blood pressure greater than or equal to $140 \mathrm{mmHg}$. However, when $\mathrm{HC}$ is higher than 110.5, WHR is higher than 0.865, and BMI is smaller than 31.45 , the person is classified as having regular systolic blood pressure (REGULAR). In fact, $80 \%$ of men with these characteristics have a systolic blood pressure lower than $140 \mathrm{mmHg}$. On one hand, averaging the percentage of men with increased blood pressure (or systolic hypertension) classified as having hypertension in each node results in a correct prediction of $72 \%$ (overall tree sensibility). On the other hand, averaging the percentage of men with regular blood pressure classified as having a regular pressure in each node results in a correct prediction of $86.25 \%$ (overall 


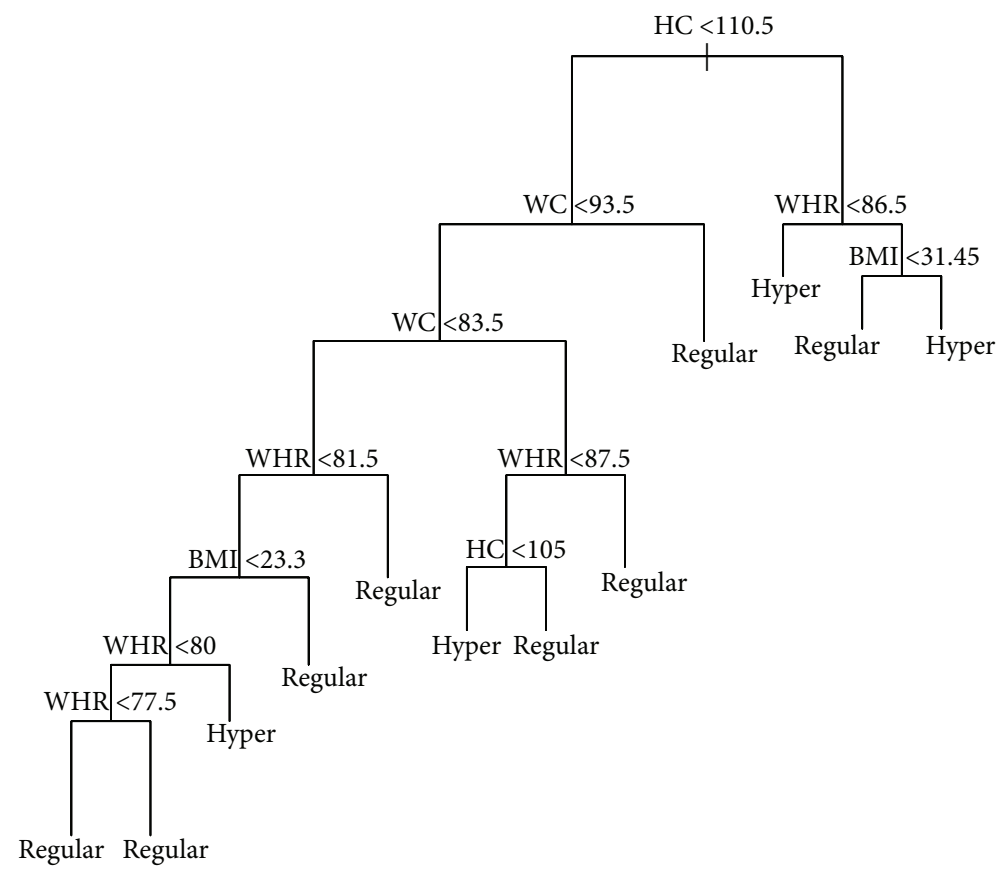

FIgURE 2: Best model for men. Notice that the endpoint for men is greater than $140 \mathrm{mmHg}$ (hypertension).

tree specificity). However, the cross-validation of tree 15 in men's testing sample showed that the sensibility decreased to $52.38 \%$ and the specificity to $69.70 \%$. The percentage of men with SBP greater than or equal to $140 \mathrm{mmHg}$ in the training sample was $30 \%$ and in the testing sample was $24.13 \%$.

Comparing the strength of the predictions made, it is clear that classification trees outperformed traditional logistic regression. The best predictive model for women generated using classification trees had a pseudo- $R^{2}$ of 0.43 , with an overall tree sensibility of $80.86 \%$ and specificity of $81.22 \%$, while the logistic model with higher pseudo- $R^{2}$ and AUC was the model 11 , presenting 0.023 and 0.566 , respectively (see Table 3 ). The best classification tree for men presented a pseudo- $R^{2}$ of 0.466 with an overall sensibility of $72 \%$ and specificity of $86.25 \%$, while the logistic model with higher pseudo- $R^{2}$ and AUC was the model 12, presenting 0.13 and 0.68 respectively (see Table 4 ).

\section{Conclusions}

According to the Harvard Obesity Prevention Source [29], it is estimated that 500 million adults are obese and 1.5 billion are overweight or obese worldwide. Obesity is a public health problem that affects approximately 1.5 million people each year in Brazil [30] and is responsible for a huge amount of money, about U\$ 240 million dollars in 2011 [31], to directly treat it or to treat several related diseases. This chronic noncommunicable disease had its prevalence increased in both developed and in development countries, affecting, for example, $35.5 \%$ of women and $32.2 \%$ of adult men in the USA [2] and $12.4 \%$ of men and $16.9 \%$ of women in Brazil [3]. At least three pathophysiological mechanisms are known to link obesity to increased blood pressure. The first one is related to visceral obesity, indicating that mesenteric and omental adipocytes are more active than the subcutaneous ones [32], contributing to endothelial dysfunction, which may contribute to increasing blood pressure in obese people. The other two mechanisms involve the sympathetic nervous system $[33,34]$ and the imbalance in the homeostasis of plasma sodium [35-37] that are related to the extracellular volume increase and, thus, contribute to blood pressure elevation in people with obesity.

Anthropometric variables are among the most practical and low-cost obesity diagnostic methods [38], regarding their limitations and issues [38, 39]. World Health Organization 2008's report [40] points that body mass index, waist circumference, and waist-hip ratio are related to risk of cardiovascular diseases, hypertension, overall mortality, and other health problems. The same report points that additional information can be provided by hip circumference in the diagnosis of obesity, since it is related to gluteofemoral muscle mass and bone structure. Previous studies have pointed to the cutoff values of the anthropometric variables that are related to blood pressure $[9,41]$. The cut-off values are different across ethnicities [40, 42], samples, age, and risk factors investigated [43]. All the studies quoted above employed traditional data analysis procedures, such as linear or logistic regression and the ROC curve analysis to verify the predictive role for each variable and to discover the best cutoff values for them. The use of null-hypothesis significance testing ( $P$ value) requires caution to verify which variables better predict obesity. A smaller $P$ does not indicate a stronger relationship between independent and dependent variables, and statistical significance does not indicate practical importance [44]. The ROC curve analysis is highly recommended in epidemiological 
TABLE 3: Logistic regression results of women's training set.

\begin{tabular}{|c|c|c|c|c|c|c|}
\hline & Coefficients & S.E & Wald $Z$ & $P$ & Pseudo $R^{2}$ & AUC \\
\hline \multicolumn{7}{|l|}{ Model 1} \\
\hline Intercept & 17.615 & 12.206 & 1.44 & 0.1490 & \multirow{2}{*}{0.019} & \multirow{2}{*}{0.548} \\
\hline BMI & -0.0651 & 0.0519 & -1.25 & 0.2095 & & \\
\hline \multicolumn{7}{|l|}{ Model 2} \\
\hline Intercept & 20.584 & 17.149 & 1.20 & 0.2300 & \multirow{2}{*}{0.014} & \multirow{2}{*}{0.529} \\
\hline WC & -0.0236 & 0.0223 & -1.06 & 0.2886 & & \\
\hline \multicolumn{7}{|l|}{ Model 3} \\
\hline Intercept & 18.701 & 22.687 & 0.82 & 0.4098 & \multirow{2}{*}{0.006} & \multirow{2}{*}{0.542} \\
\hline $\mathrm{HC}$ & -0.0160 & 0.0224 & -0.72 & 0.4737 & & \\
\hline \multicolumn{7}{|l|}{ Model 4} \\
\hline Intercept & 25.470 & 29.026 & 0.88 & 0.3802 & \multirow{2}{*}{0.008} & \multirow{2}{*}{0.539} \\
\hline WHR & -0.0303 & 0.0382 & -0.79 & 0.4278 & & \\
\hline \multicolumn{7}{|l|}{ Model 5} \\
\hline Intercept & 17.497 & 17.739 & 0.99 & 0.3240 & \multirow{3}{*}{0.019} & \multirow{3}{*}{0.549} \\
\hline BMI & -0.0659 & 0.0973 & -0.68 & 0.4987 & & \\
\hline WC & 0.0004 & 0.0418 & 0.01 & 0.9927 & & \\
\hline \multicolumn{7}{|l|}{ Model 6} \\
\hline Intercept & 0.5958 & 25.251 & 0.24 & 0.8135 & \multirow{3}{*}{0.022} & \multirow{3}{*}{0.572} \\
\hline BMI & -0.1030 & 0.0891 & -1.16 & 0.2477 & & \\
\hline $\mathrm{HC}$ & 0.0203 & 0.0386 & 0.53 & 0.5993 & & \\
\hline \multicolumn{7}{|l|}{ Model 7} \\
\hline Intercept & 26.319 & 29.105 & 0.90 & 0.3658 & \multirow{3}{*}{0.020} & \\
\hline BMI & -0.0579 & 0.0562 & -1.03 & 0.3025 & & 0.541 \\
\hline WHR & -0.0137 & 0.0414 & -0.33 & 0.7414 & & \\
\hline Model 8 & & & & & & \\
\hline Intercept & 16.879 & 22.829 & 0.74 & 0.4597 & & \\
\hline WC & -0.0311 & 0.0378 & -0.82 & 0.4103 & 0.014 & 0.534 \\
\hline $\mathrm{HC}$ & 0.0093 & 0.0381 & 0.25 & 0.8063 & & \\
\hline Model 9 & & & & & & \\
\hline Intercept & 23.660 & 29.157 & 0.81 & 0.4171 & & \\
\hline WC & -0.0211 & 0.0293 & -0.72 & 0.4711 & 0.014 & 0.529 \\
\hline WHR & -0.0066 & 0.0503 & -0.13 & 0.8961 & & \\
\hline Model 10 & & & & & & \\
\hline Intercept & 38.639 & 35.464 & 1.09 & 0.2759 & & \\
\hline $\mathrm{HC}$ & -0.0146 & 0.0225 & -0.65 & 0.5151 & 0.013 & 0.529 \\
\hline WHR & -0.0282 & 0.0383 & -0.73 & 0.4626 & & \\
\hline Model 11 & & & & & & \\
\hline Intercept & 0.6938 & 25.681 & 0.27 & 0.7870 & & \\
\hline BMI & -0.0904 & 0.1069 & -0.85 & 0.3976 & 0023 & 0.566 \\
\hline WC & -0.0097 & 0.0454 & -0.21 & 0.8317 & 0.023 & 0.566 \\
\hline $\mathrm{HC}$ & 0.0237 & 0.0419 & 0.57 & 0.5711 & & \\
\hline Model 12 & & & & & & \\
\hline Intercept & -235.909 & 29.736 & $6-0.79$ & 0.427 & & \\
\hline WC & -0.3548 & 0.382 & $1-0.93$ & 0.353 & 0.023 & 0.539 \\
\hline $\mathrm{HC}$ & 0.2571 & 0.293 & 50.88 & 0.381 & 0.020 & 0.539 \\
\hline WHR & 0.3303 & 0.387 & 50.85 & 0.394 & & \\
\hline Model 13 & & & & & & \\
\hline Intercept & 28.202 & 29.786 & 0.95 & 0.3437 & & \\
\hline BMI & -0.0856 & 0.1070 & -0.80 & 0.4239 & 0021 & 0558 \\
\hline WC & 0.0170 & 0.0559 & 0.30 & 0.7609 & 0.021 & 0.538 \\
\hline WHR & -0.0249 & 0.0554 & -0.45 & 0.6538 & & \\
\hline
\end{tabular}


TABLe 3: Continued.

\begin{tabular}{|c|c|c|c|c|c|c|}
\hline & Coefficients & S.E & Wald $Z$ & $P$ & Pseudo $R^{2}$ & AUC \\
\hline \multicolumn{7}{|l|}{ Model 14} \\
\hline Intercept & 10.603 & 46.901 & 0.23 & 0.8211 & \multirow{4}{*}{0.022} & \multirow{4}{*}{0.566} \\
\hline BMI & -0.0962 & 0.1061 & -0.91 & 0.3646 & & \\
\hline $\mathrm{HC}$ & 0.0181 & 0.0426 & 0.43 & 0.6699 & & \\
\hline WHR & -0.0054 & 0.0458 & -0.12 & 0.9064 & & \\
\hline \multicolumn{7}{|l|}{ Model 15} \\
\hline Intercept & -22.3777 & 29.6673 & -0.75 & 0.4507 & \multirow{5}{*}{0.030} & \multirow{5}{*}{0.57} \\
\hline BMI & -0.0833 & 0.1078 & -0.77 & 0.4399 & & \\
\hline WC & -0.3078 & 0.3851 & -0.80 & 0.4242 & & \\
\hline $\mathrm{HC}$ & 0.2495 & 0.2926 & 0.85 & 0.3939 & & \\
\hline WHR & 0.3025 & 0.3876 & 0.78 & 0.4351 & & \\
\hline
\end{tabular}

Notice that the endpoint for women is systolic blood pressure greater than $120 \mathrm{mmHg}$ (prehypertension), while for men is greater than $140 \mathrm{mmHg}$ (hypertension).

studies [45] because it can describe the accuracy of a variable to classify people into relevant clinical groups. However, the ROC curve methodology is not an informative technique to evaluate the contribution of an additional variable to the model [14], being limited to investigate the improvement in the prediction or in the amount of variance explained when an additional variable enters the model (incremental validity). In order to identify the role of BMI, WC, WHR, and $\mathrm{HC}$ together in the prediction of increased blood pressure it is necessary to employ a statistical method that can provide sensitive information about incremental validity.

A conjoint of techniques that can provide sensitive information about incremental validity is the classification and regression tree (CART) of the machine learning field. The CART techniques are of special interest for health studies to discover which variable, or combination of variables, better predicts a given outcome (e.g., presence of increased blood pressure) and to identify the cutoff values for each variable that maximally predicts the chosen outcome. Health studies have been employing machine learning methods in different applications that go from sustained weight loss investigation [46], obesity prediction [17], to genetic [21] and medical image data analysis [22].

In the current study, classification tree models were used to verify which combination of BMI, WC, WHR, and HC best predicted increased blood pressure for women and men. The best model for women showed that adding WC and WHR to $\mathrm{BMI}$ increased $11 \%$ of the variance explanation in the predictive model, decreased the percentage of misclassification from $26 \%$ to $19 \%$, and decreased deviance from 104.50 to 87.42. As pointed before, WC and WHR have a considerable impact on the prediction of increased blood pressure in women when combined with BMI. The overall sensibility for the best model (tree no. 13) was $80.86 \%$ and the overall specificity was $81.22 \%$. The complex model represented by tree 13 (see Figure 1) exceeded the sensitivity and specificity found in previous studies. Yong et al. [9] found sensibility and specificity of $60 \%$ and $67 \%$ for WC, $83 \%$ and $40 \%$ for WHR, and $75 \%$ and $59 \%$ for BMI in the women sample. A Brazilian study investigating the predictive role of BMI in hypertension in 1,298 people (52.5\% of women) found an area under the ROC curve of 0.69 (95\% C.I.: 0.64-0.74) for women [47].

The best model for men showed that WC, HC, WHR, and BMI together presented an incremental validity over BMI alone in the prediction of hypertension, increasing $30 \%$ of the variance explanation, improving $10 \%$ of misclassification, and decreasing deviance from 89.35 to 57.25 . The overall sensibility and specificity for the best model (tree no. 15) was $72 \%$ and $86.25 \%$. As happened with the women result, the complex model represented by tree 15 (see Figure 2) exceeded the sensitivity and specificity found in previous studies. Furthermore, compared to traditional logistic regression analysis, the classification trees produced a much better prediction, with higher pseudo- $R^{2}$, sensibility, and specificity for both men and women.

In spite of the high sensibility and specificity of the best models for both men and women in the training sample, the cross validation applied in the test sample revealed a different scenario. The cross-validation of tree 13 in women's testing sample showed that the sensibility decreased to $45.65 \%$ and the specificity to $65.15 \%$, and the cross-validation of tree 15 in the men's testing sample showed that sensibility decreased to $52.38 \%$ and the specificity decreased to $69.70 \%$. The observed difference in sensibility and specificity between the modeled training set and the cross-validation in the test set is known in the machine learning literature as the variance issue [28]. It means that the algorithm learned too much from the observed data and is likely to make more errors in a different data set. So, we need to interpret the present result and the best model for both men and women with caution. The variance issue that emerged from our study can also emerge in studies using more traditional statistical methods, such as the ROC curve analysis. It is important to make subset of the sample gathered in order to apply cross-validation. The result found by Abolfotouh and colleagues [8], or by every other investigation made that did not use a cross-validation procedure, may be susceptible of the variance issue. However, overfitting is more usual in the machine learning techniques than in the traditional ones. In order to overcome overfitting in the classification and regression tree's method, a bootstrap 
TABLE 4: Logistic regression results of men's training set.

\begin{tabular}{|c|c|c|c|c|c|c|}
\hline & Coefficients & S.E & Wald $Z$ & $P$ & Pseudo $R^{2}$ & AUC \\
\hline \multicolumn{7}{|l|}{ Model 1} \\
\hline Intercept & 3.27 & 1.41 & 2.32 & 0.02 & \multirow{2}{*}{0.05} & \multirow{2}{*}{0.597} \\
\hline BMI & -0.09 & 0.05 & -1.74 & 0.08 & & \\
\hline \multicolumn{7}{|l|}{ Model 2} \\
\hline Intercept & 3.28 & 1.73 & 1.89 & 0.05 & \multirow{2}{*}{0.03} & \multirow{2}{*}{0.591} \\
\hline WC & -0.02 & 0.01 & -1.42 & 0.15 & & \\
\hline \multicolumn{7}{|l|}{ Model 3} \\
\hline Intercept & 7.99 & 3.05 & 2.62 & 0.008 & \multirow{2}{*}{0.09} & \multirow{2}{*}{0.656} \\
\hline $\mathrm{HC}$ & -0.06 & 0.02 & -2.36 & 0.0183 & & \\
\hline \multicolumn{7}{|l|}{ Model 4} \\
\hline Intercept & 0.12 & 3.15 & 0.04 & 0.96 & \multirow{2}{*}{0.001} & \multirow{2}{*}{0.498} \\
\hline WHR & 0.0089 & 0.03 & 0.24 & 0.8120 & & \\
\hline \multicolumn{7}{|l|}{ Model 5} \\
\hline Intercept & 28.040 & 17.829 & 1.57 & 0.1158 & \multirow{3}{*}{0.05} & \multirow{3}{*}{0.596} \\
\hline BMI & -0.1416 & 0.1222 & -1.16 & 0.2463 & & \\
\hline WC & 0.0193 & 0.0442 & 0.44 & 0.6628 & & \\
\hline \multicolumn{7}{|l|}{ Model 6} \\
\hline Intercept & 106.641 & 42.606 & 2.50 & 0.0123 & \multirow{3}{*}{0.10} & \multirow{3}{*}{0.667} \\
\hline BMI & 0.1117 & 0.1202 & 0.93 & 0.3528 & & \\
\hline $\mathrm{HC}$ & -0.1213 & 0.0645 & -1.88 & 0.0601 & & \\
\hline \multicolumn{7}{|l|}{ Model 7} \\
\hline Intercept & -15.975 & 33.454 & -0.48 & 0.6330 & \multirow{3}{*}{0.09} & \\
\hline BMI & -0.1641 & 0.0710 & -2.31 & 0.0207 & & 0.636 \\
\hline WHR & 0.0797 & 0.0499 & 1.60 & 0.1105 & & \\
\hline Model 8 & & & & & & \\
\hline Intercept & 101.735 & 35.689 & 2.85 & 0.0044 & & \\
\hline WC & 0.0532 & 0.0404 & 1.32 & 0.1883 & 0.12 & 0.672 \\
\hline $\mathrm{HC}$ & -0.1339 & 0.0587 & -2.28 & 0.0226 & & \\
\hline Model 9 & & & & & & \\
\hline Intercept & -49.908 & 38.546 & -1.29 & 0.1954 & & \\
\hline WC & -0.1085 & 0.0399 & -2.72 & 0.0065 & 0.13 & 0.677 \\
\hline WHR & 0.1836 & 0.0770 & 2.38 & 0.0172 & & \\
\hline Model 10 & & & & & & \\
\hline Intercept & 49.970 & 36.852 & 1.36 & 0.1751 & & \\
\hline $\mathrm{HC}$ & -0.0904 & 0.0339 & -2.67 & 0.0077 & 0.12 & 0.678 \\
\hline WHR & 0.0633 & 0.0451 & 1.40 & 0.1602 & & \\
\hline Model 11 & & & & & & \\
\hline Intercept & 106.368 & 42.926 & 2.48 & 0.0132 & & \\
\hline BMI & 0.0284 & 0.1449 & 0.20 & 0.8447 & 0.12 & 0.671 \\
\hline WC & 0.0479 & 0.0485 & 0.99 & 0.3234 & & \\
\hline $\mathrm{HC}$ & -0.1408 & 0.0686 & -2.05 & 0.0400 & & \\
\hline Model 12 & & & & & & \\
\hline Intercept & -208.656 & 32.535 & $2-0.6$ & 40.521 & & \\
\hline WC & -0.2790 & 0.350 & $1-0.8$ & 00.425 & 0.13 & 0.680 \\
\hline $\mathrm{HC}$ & 0.1460 & 0.296 & 70.4 & 90.622 & & 0.000 \\
\hline WHR & 0.3697 & 0.387 & 90.9 & 50.340 & & \\
\hline Model 13 & & & & & & \\
\hline Intercept & -55.980 & 41.837 & -1.34 & 0.1809 & & \\
\hline BMI & 0.0537 & 0.1476 & 0.36 & 0.7161 & 013 & 0681 \\
\hline WC & -0.1345 & 0.0820 & -1.64 & 0.1013 & 0.15 & 0.001 \\
\hline WHR & 0.2015 & 0.0916 & 2.20 & 0.0279 & & \\
\hline
\end{tabular}


TABLE 4: Continued.

\begin{tabular}{lccccc}
\hline & Coefficients & S.E & Wald $Z$ & $P$ & Pseudo $R^{2}$ \\
\hline Model 14 & & & & & \\
Intercept & 57.797 & 60.170 & 0.96 & 0.3368 & 0.12 \\
BMI & 0.0234 & 0.1420 & 0.16 & 0.8691 & 0.679 \\
HC & -0.0999 & 0.0671 & -1.49 & 0.1364 & 0.2687 \\
WHR & 0.0586 & 0.0530 & 1.11 & & 0.139 \\
Model 15 & & & & 0.4873 & 0.689 \\
Intercept & -22.9141 & 32.9873 & -0.69 & 0.3785 & \\
BMI & 0.0614 & 0.1482 & 0.41 & 0.5960 & 0.3089 \\
WC & -0.3231 & 0.3669 & -0.88 & 0.53 & \\
HC & 0.1582 & 0.2985 & 0.3993 & 1.02 & 0.3089 \\
WHR & 0.4062 & & & & \\
\hline
\end{tabular}

procedure named Random Forests [48] can be applied. It bootstraps samples and variables, grows multiple trees, enables greater accuracy, and avoids overfitting, being one of the best procedures for dealing with the variance issue [28]. Finally, we must address the limitations of the current study. Firstly, it did not employ a representative sample randomly chosen, relying on a convenience sample. It makes our inferences limited. Secondly, the number of women with hypertension was very low, obligating us to analyze increased blood pressure in them and hypertension in men, which compromised the comparison of the findings between sexes. Those issues should be solved in future researches. Finally, our results cannot be generalized to other ethnics, but the methodology adopted in the current paper could be used in data gathered in different countries to construct new predictive models of increased blood pressure.

Using machine learning techniques to discover new relations in data, to verify incremental validity of additional predictors, and to make accurate predictions for new data sets may help the health scientists to find new robust diagnostic parameters. The clinical usefulness of the present study relies on the possibility of using new algorithms to classify and predict increased blood pressure, with higher accuracy than usual cutoff points. Although most of the clinicians can measure both blood pressure and the anthropometric variables simultaneously, there are several parts of the world, such as many countries from Africa or several places in Latin America, where material resources are scarce. So, the application of complex algorithms, as the presented one in the current paper, can be a help for those professionals that can rely only on very simple and cheap instruments, such as a measure tape. Furthermore, the present study applied a new method for prediction of health outcomes, which in spite of being incipient in the literature, can provide new insights and discoveries since it outperforms traditional techniques (such as logistic and linear regression), making possible to compare the impact of new variables on the prediction of the chosen outcome (incremental validity). Traditional techniques are based on several assumptions, as the normality of the distribution, linear relationship between independent and dependent variables, homoscedasticity, and so on. The Machine learning techniques can handle any kind of variable (ordinal, continuous, dichotomous, and nominal), with no assumption about distribution, linearity, or homoscedasticity. Moreover, it can be used to extract useful information and to discover new relations in very huge data sets provided by some international databases, such as the World Health Organization Global database on noncommunicable diseases (see http://www.who.int/gho/ncd/en/index.html) [49]. As quoted in the introduction, the data deluge can transform the society, and machine learning will play a pivotal role in it. Future researches should overcome the limitations of the present study by employing a larger and representative sample, by using strategies to minimize the variance issue, especially the Random Forest [48] approach.

\section{Conflict of Interests}

The authors declare that there is no conflict of interests regarding the publication of this paper.

\section{Acknowledgments}

The authors are thankful for the grant received by the Fundação de Amparo à Pesquisa do Estado da Bahia (FAPESB) and for the financial support of the Faculdade Independente do Nordeste.

\section{References}

[1] P. Hossain, B. Kawar, and M. Nahas, "Obesity and diabetes in the developing world-a growing challenge," The New England Journal of Medicine, vol. 356, no. 3, pp. 213-215, 2007.

[2] K. M. Flegal, M. D. Carroll, C. L. Ogden, and L. R. Curtin, "Prevalence and trends in obesity among US adults, 1999-2008," Journal of the American Medical Association, vol. 303, no. 3, pp. 235-241, 2010.

[3] IBGE-Instituto Brasileiro de Geografia e Estatística, "POF, 2008-2009: desnutrição cai e peso das crianças Brasileiras ultrapassa padrão internacional," 2010, http://saladeimprensa. ibge.gov. br/noticias? view=noticia\&id $=1 \&$ busca $=1 \&$ idnoticia $=$ 1699.

[4] G. Gürsoy, S. Ulu, Y. Acar et al., "Relation of resistın with obesity and some cardiovascular risk factors in hypertensive women," 
Journal of Research in Medical Sciences, vol. 17, no. 5, pp. 443447, 2012.

[5] E. Ugwuja, N. Ogbonna, A. Nwibo, and I. A. Onimawo, "Overweight and obesity, lipid profile and atherogenic indices among civil servants in Abakaliki, south eastern Nigeria," Annals of Medical and Health Sciences Research, vol. 3, no. 1, pp. 13-18, 2013.

[6] M. Dalton, A. J. Cameron, P. Z. Zimmet et al., "Waist circumference, waist-hip ratio and body mass index and their correlation with cardiovascular disease risk factors in Australian adults," Journal of Internal Medicine, vol. 254, no. 6, pp. 555-563, 2003.

[7] O. Perichart-Perera, M. Balas-Nakash, E. Schiffman-Selechnik, A. Barbato-Dosal, and F. Vadillo-Ortega, "Obesity increases metabolic syndrome risk factors in school-aged children from an urban school in Mexico City," Journal of the American Dietetic Association, vol. 107, no. 1, pp. 81-91, 2007.

[8] M. A. Abolfotouh, I. A. Al-Alwan, and M. A. Al-Rowaily, "Prevalence of metabolic abnormalities and association with obesity among Saudi college students," International Journal of Hypertension, vol. 2012, Article ID 819726, 8 pages, 2012.

[9] L. Yong, T. Guanghui, T. Weiwei, L. Liping, and Q. Xiaosong, "Can body mass index, waist circumference, waist-hip ratio and waist-height ratio predict the presence of multiple metabolic risk factors in Chinese subjects?" BMC Public Health, vol. 11, article 35, 2011.

[10] J. B. Dixon, B. J. G. Strauss, C. Laurie, and P. C. O’Brien, "Smaller hip circumference is associated with dyslipidemia and the metabolic syndrome in obese women," Obesity Surgery, vol. 17, no. 6, pp. 770-777, 2007.

[11] Y. Wang, E. B. Rimm, M. J. Stampfer, W. C. Willett, and F. B. $\mathrm{Hu}$, "Comparison of abdominal adiposity and overall obesity in predicting risk of type 2 diabetes among men," American Journal of Clinical Nutrition, vol. 81, no. 3, pp. 555-563, 2005.

[12] M. A. Beydoun, M. T. Kuczmarski, Y. Wang, M. A. Mason, M. K. Evans, and A. B. Zonderman, "Receiver-operating characteristics of adiposity for metabolic syndrome: the healthy aging in neighborhoods of diversity across the life span (HANDLS) study," Public Health Nutrition, vol. 14, no. 1, pp. 77-92, 2011.

[13] L. S. Erdreich and E. T. Lee, "Use of relative operating characteristic analysis in epidemiology. A method for dealing with subjective judgement," American Journal of Epidemiology, vol. 114, no. 5, pp. 649-662, 1981.

[14] T. Hastie, R. Tibshirani, and J. Friedman, The Elements of Statistical Learning, Springer, Berlin, Germany, 2nd edition, 2009.

[15] Y.-C. Lee, W.-J. Lee, Y.-C. Lin et al., "Obesity and the decision tree: predictors of sustained weight loss after bariatric surgery," Hepatogastroenterology, vol. 56, no. 96, pp. 1745-1749, 2009.

[16] P. Hertzman, "The cost effectiveness of orlistat in a 1-year weight-management programme for treating overweight and obese patients in Sweden: a treatment responder approach," PharmacoEconomics, vol. 23, no. 10, pp. 1007-1020, 2005.

[17] A. Bhattarai, V. Rus, and D. Dasgupta, "Classification of clinical conditions: a case study on prediction of obesity and its comorbidities," in Proceedings of the 10th International Conference on Intelligent Text Processing and Computational Linguistics (CICLING '09), Mexico City, Mexico, March 2009.

[18] O. Regnier-Coudert, J. McCall, R. Lothian, T. Lam, S. McClinton, and J. N'Dow, “Machine learning for improved pathological staging of prostate cancer: a performance comparison on a range of classifiers," Artificial Intelligence in Medicine, vol. 55, no. 1, pp. 25-35, 2012.
[19] J. T. Pollettini, S. R. Panico, J. C. Daneluzzi, R. Tinós, J. A. Baranauskas, and A. A. Macedo, "Using machine learning classifiers to assist healthcare-related decisions: classification of electronic patient records," Journal of Medical Systems, vol. 36, no. 6, pp. 3861-3874, 2012.

[20] D. Page, "Predicting clinical events from electronic health records," in Proceedings of the Microsoft Research Machine Learning Summit, Issy-les-Moulineaux, France, 2013.

[21] K. Sharp, W. Wiegerinck, W. Burgers et al., "Searching for genetic dark matter," in Proceedings of the Microsoft Research Machine Learning Summit, Issy-les-Moulineaux, France, 2013.

[22] A. Criminisi, "Machine learning for medical image analysis," in Proceedings of the Microsoft Research Machine Learning Summit, Paris, France, 2013.

[23] J. T. Leek, "Predicting with trees. Coursera's data analysis class material," 2013, https://github.com/jtleek/dataanalysis.

[24] T. G. Lohman, A. F. Roche, and R. Martorell, Anthropometric Standardization Reference Manual, Human Kinetics Books, Champaign, Ill, USA, 1988.

[25] H. Golino, "Women's dataset from the "Predicting increased blood pressure using machine learning” paper," Figshare, 2013.

[26] H. Golino, "Men's dataset from the "Predicting increased blood pressure using machine learning" paper," Figshare, 2013.

[27] B. D. Ripley, "Package "tree": classification and regression trees. R package version 1.0-33," 2013, http://cran.r-project.org/web/ packages/tree.

[28] P. Geurts, A. Irrthum, and L. Wehenkel, "Supervised learning with decision tree-based methods in computational and systems biology," Molecular Biosystems, vol. 5, no. 12, pp. 1593-1605, 2009.

[29] Harvard Obesity Prevention Source, Harvard School of Public Health, Cambridge, Mass, USA, http://www.hsph.harvard.edu/ obesity-prevention-source/.

[30] Ministério da Saúde, "Vigilância de fatores de risco e proteção para doenças crônicas por inquérito telefônico," Ministério da Saúde, Brasília, Brasil, 2011, http://portalsaude.saude.gov.br/ portalsaude/arquivos/pdf/2012/Ago/22/vigite_2011_final_0812. pdf.

[31] M. L. Oliveira, Estimativa dos custos da obesidade para o sistema único de saúde do Brasil [Ph.D. thesis], UnB, Brasília, Brasil, 2013.

[32] R. K. Dubey and E. K. Jackson, "Estrogen-induced cardiorenal protection: potential cellular, biochemical, and molecular mechanisms," American Journal of Physiology, vol. 280, no. 3, pp. F365-F388, 2001.

[33] J. E. Hall, “The kidney, hypertension, and obesity," Hypertension, vol. 41, no. 3, part 2, pp. 625-633, 2003.

[34] L. Landsberg, "Diet, obesity and hypertension: an hypothesis involving insulin, the sympathetic nervous system, and adaptive thermogenesis," Quarterly Journal of Medicine, vol. 61, no. 236, pp. 1081-1090, 1986.

[35] J. E. Hall, "Mechanisms of abnormal renal sodium handling in obesity hypertension," American Journal of Hypertension, vol. 10, no. 5, part 2, pp. S49-S55, 1997.

[36] V. Kotsis, S. Stabouli, S. Papakatsika, Z. Rizos, and G. Parati, "Mechanisms of obesity-induced hypertension," Hypertension Research, vol. 33, no. 5, pp. 386-393, 2010.

[37] J. E. Hall, A. A. da Silva, J. M. do Carmo et al., "Obesity-induced hypertension: role of sympathetic nervous system, leptin, and melanocortins," Journal of Biological Chemistry, vol. 285, no. 23, pp. 17271-17276, 2010. 
[38] World Health Organization, "Obesity: preventing and managing the global epidemic," Report of a WHO Consultation WHO Technical Report Series 894, WHO, Geneva, Switzerland, 2000.

[39] G. Velasquez-Melendez, A. M. Pimenta, and G. Kac, "Epidemiologia do sobrepeso e da obesidade e seus fatores determinantes em Belo Horizonte (MG), Brasil: estudo transversal de base populacional," Revista Panamericana de Salud Publica, vol. 16, no. 5, pp. 308-314, 2004.

[40] World Health Organization, "Waist circumference and waisthip ratio," Report of a WHO Expert ConsultAtion, WHO, Geneva, Switzerland, 2008.

[41] O. S. Adediran, P. B. Adebayo, and A. A. Akintunde, "Anthropometric differences among natives of Abuja living in urban and rural communities: correlations with other cardiovascular risk factors," BMC Research Notes, vol. 6, article 123, 2013.

[42] A. Misra, N. Vikram, R. Gupta, R. Pandey, V. Gupta, and J. Wasir, "Waist circumference cutoff points and action levels for Asian Indians for identification of abdominal obesity," International Journal of Obesity, vol. 30, no. 1, pp. 106-111, 2006.

[43] C. J. Dobbelsteyn, M. R. Joffres, D. R. MacLean, and G. Flowerdew, "A comparative evaluation of waist circumference, waistto-hip ratio and body mass index as indicators of cardiovascular risk factors. The Canadian heart health surveys," International Journal of Obesity, vol. 25, no. 5, pp. 652-661, 2001.

[44] J. A. Gliner, N. Leech, and G. Morgan, "Problems with null hypothesis significance testing (NHST): what do the textbooks say?" Journal of Experimental Education, vol. 71, no. 1, pp. 83-92, 2002.

[45] L. S. Erdreich and E. T. Lee, "Use of relative operating characteristic analysis in epidemiology. A method for dealing with subjective judgement," American Journal of Epidemiology, vol. 114, no. 5, pp. 649-662, 1981.

[46] Y.-C. Lee, W.-J. Lee, Y.-C. Lin et al., "Obesity and the decision tree: predictors of sustained weight loss after bariatric surgery," Hepatogastroenterology, vol. 56, no. 96, pp. 1745-1749, 2009.

[47] L. S. Barbosa, L. C. N. Scala, and M. G. Ferreira, "Associação entre marcadores antropométricos de adiposidade corporal e hipertensão arterial na população adulta de Cuiabá, Mato Grosso," Revista Brasileira de Epidemiologia, vol. 12, no. 2, pp. 237-247, 2009.

[48] L. Breiman, "Random forests," Machine Learning, vol. 45, no. 1, pp. 5-32, 2001.

[49] Global Health Organization, "Noncommunicable diseases," 2013, http://www.who.int/gho/ncd/en/index.html. 


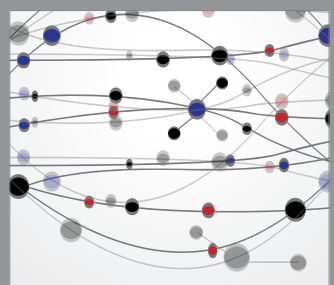

The Scientific World Journal
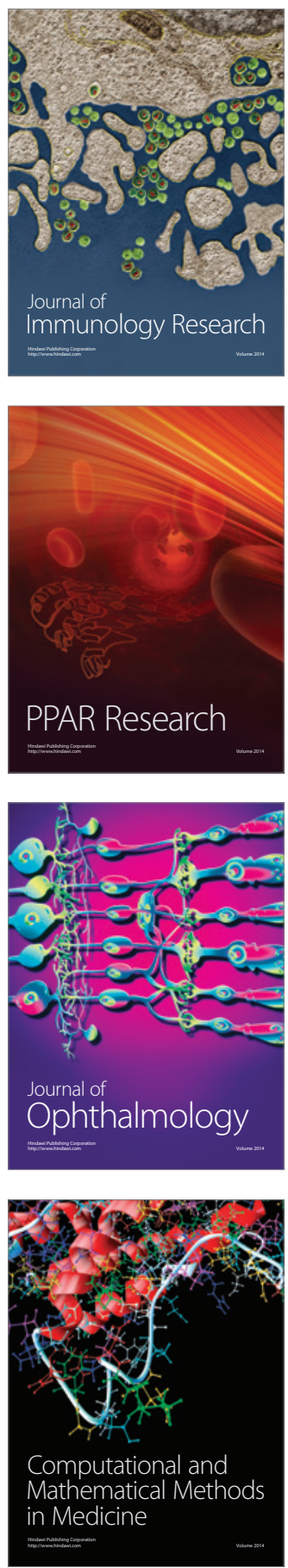

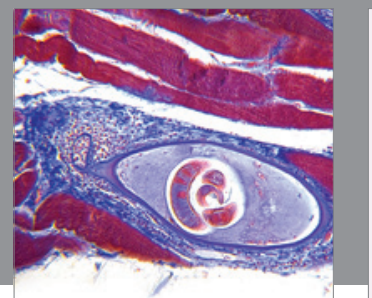

Gastroenterology

Research and Practice
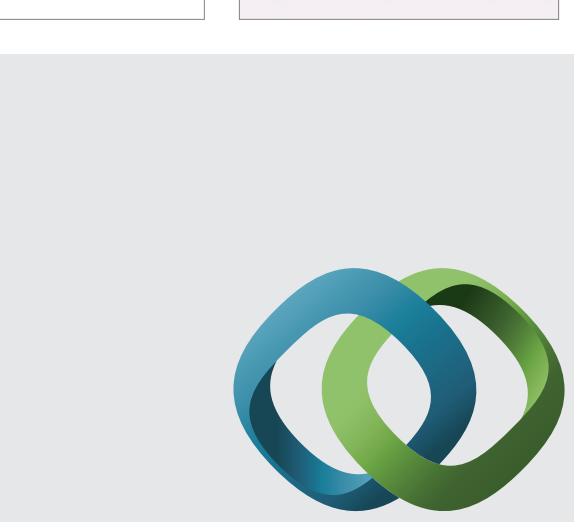

\section{Hindawi}

Submit your manuscripts at

http://www.hindawi.com
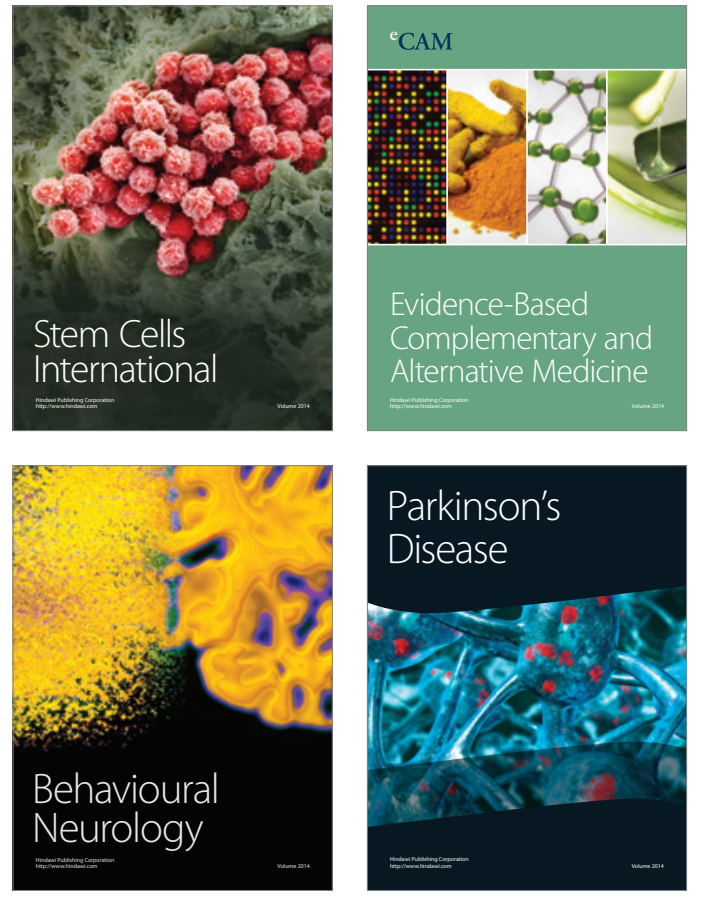
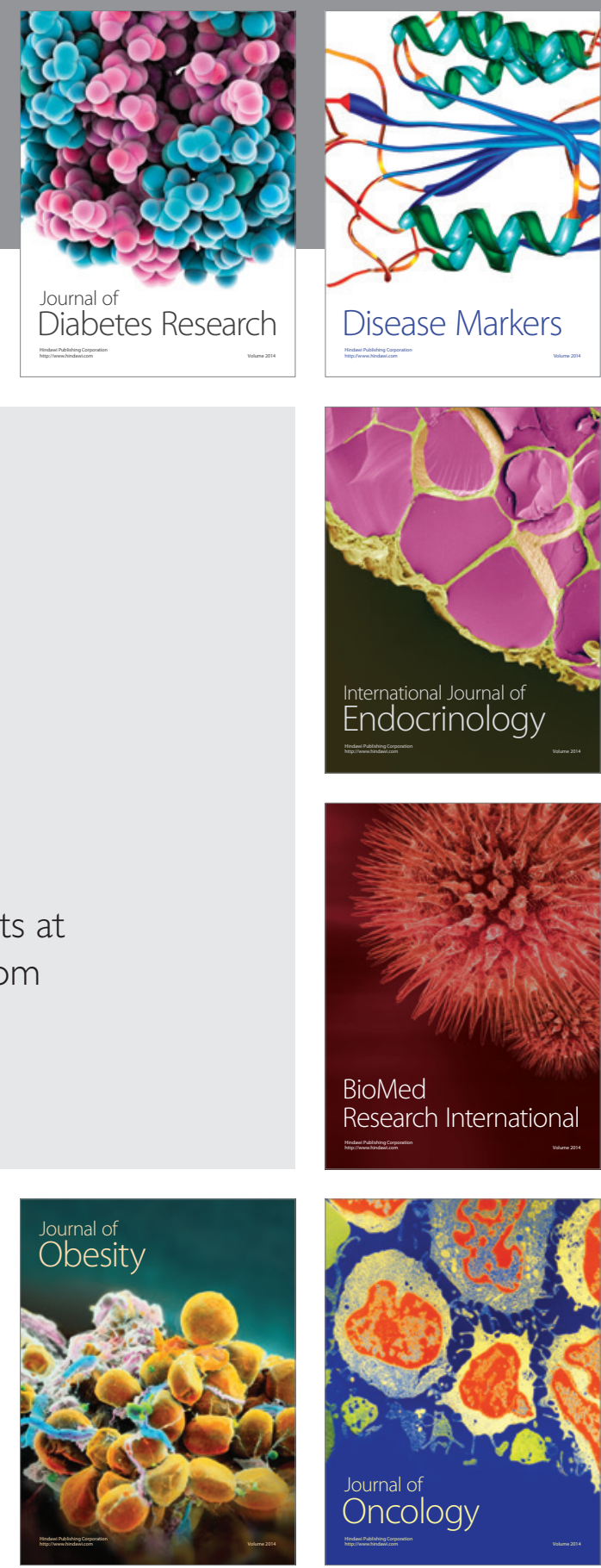

Disease Markers
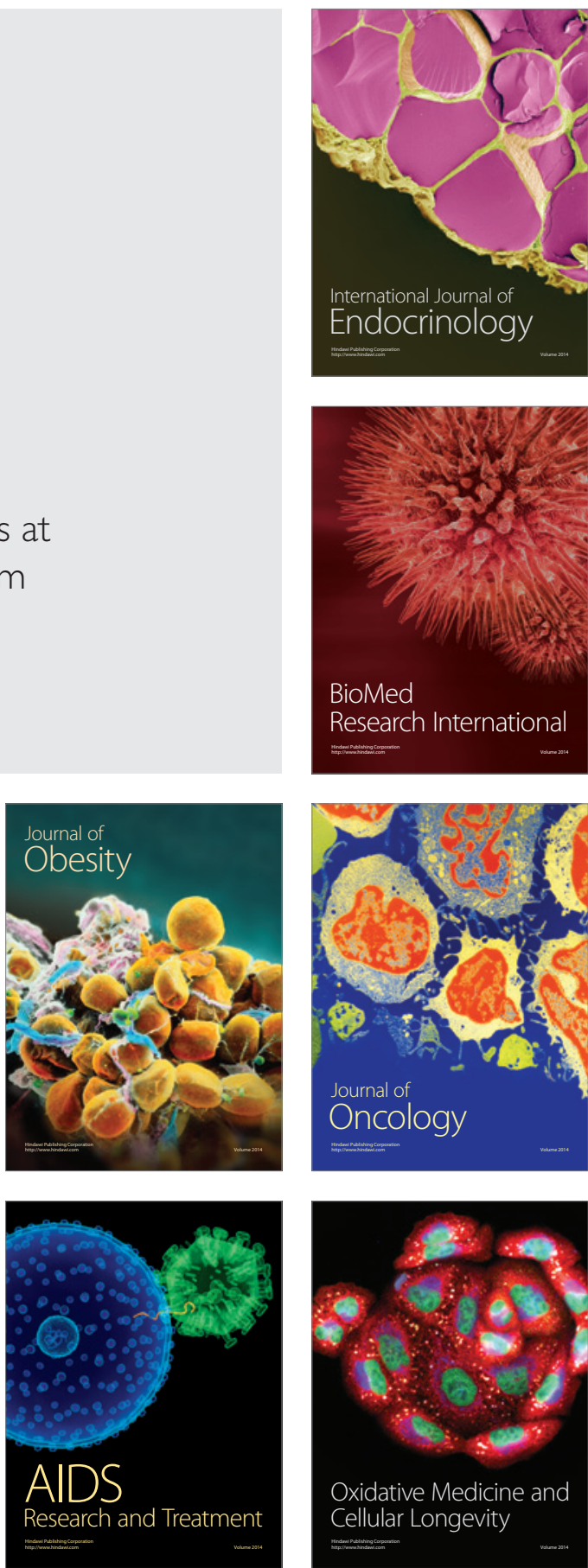